\title{
Living Arrangements and Subjective Well-Being among the Chinese Elderly
}

\author{
Li Zhang \\ China University of Political Science and Law, Beijing, China \\ Email: Izhang@cupl.edu.cn
}

Received 4 February 2015; accepted 13 March 2015; published 16 March 2015

Copyright (C) 2015 by author and Scientific Research Publishing Inc.

This work is licensed under the Creative Commons Attribution International License (CC BY). http://creativecommons.org/licenses/by/4.0/

c) (i) Open Access

\begin{abstract}
This research examines how household context mediates with social participation and intergenerational relations to impact subjective well-being among the elderly aged 65 and over in China. Through analyzing data from the $\mathbf{2 0 1 1}$ wave of Chinese Longitudinal Healthy Longevity Survey (CLHLS), the results show that living alone or in institutions links to negative well-being of the elderly. A higher level of social participation and better intergenerational relations promote positive well-being and reduce negative well-being. However, only social participation interacts with living arrangements when influencing the elderly's subjective well-being. Specifically, a higher level of social integration significantly reduces negative well-being for individuals living in institutions. The findings call future research attention to explore factors that may reduce negative well-being of the elderly living alone or living in institutions.
\end{abstract}

\section{Keywords}

Elderly, Living Arrangements, Chinese Longitudinal Healthy Longevity Survey (CLHLS), Subjective Well-Being, Aging, China

\section{Introduction}

The relationship between living arrangements and individual health and well-being has been well studied in social sciences. Different health outcomes have been considered, including subjective well-being, functional health, and mortality (Davis, Neuhaus, \& Mortitz, 1997; Kasper \& Pearson, 1995; 1984; Magaziner, Cadigan, Hebel, \& Parry, 1988; Sarwari, Fredman, \& Langenberg, 1998) [1]-[4]. Some researchers argued that the household provides an important context to individuals for social integration and various dimensions of support. Co-residence with adult children meets the needs of daily care and provides physical and emotional support to the elderly. Thus, co-residence promotes the elderly's well-being (Hughes \& Waite, 2002; Lawton, et al., 1984; Magaziner, 
et al., 1988; Sereny \& Gu, 2011; Zimmer, 2005) [3] [5]-[8]. Empirical research also supported the above argument by showing that the elderly who lived with others had the lowest mortality rate (Lund, et al., 2002) [9]. A study based on examining the elderly in Spain also found that the elderly who co-resided with children tended to have less depressive symptoms than those who lived alone (Zunzunegui, Beland, \& Otero, 2001) [10]. Other studies, however, challenged the above findings (Rook, 1984; Rook \& Pietromonaco, 1987) [11] [12]. Researchers contended that co-residence damages the elderly's health and well-being. They argued that the negative impact of co-residence on the elderly's well-being may due to the fact that relations among household members can create tensions, conflicts, and negative interaction patterns, which in turn damages the elderly's individual well-being (Krause \& Liang, 1993; Rook, 1984) [11] [13]. Such an argument has also been supported by empirical analyses. For example, studies have found that in America, living alone does not increase mortality risks among seniors (Davis, et al., 1997) [1]. Instead, many studies repeatedly showed that the elderly living alone tended to be healthier than those who lived with others. To illustrate, Sarwari and associates (1998) [4] found that living alone actually protected the elderly from deterioration in functional health status and mortality. Michael and colleagues' (Michael, Berkman, Gold, \& Kawachi, 2001) [14] research also showed that women aged 60 to 72 who lived alone had a lower risk of decline in mental health and functional status. Thus, according to the existing literature, the relationship between living arrangements and the elderly's health and well-being is not conclusive in the western social context.

In China where there is a strong tradition of filial piety and an expectation of sons providing care to the elderly, living alone is less desirable as compared with western countries. As a result, the living arrangement patterns and possible health outcomes due to various living arrangements may differ significantly across countries. Most empirical analyses based on the social context of China largely corroborated the positive impact of co-residence on the elderly's subjective well-being. For instance, $\mathrm{Li}$ and $\mathrm{Li}$ (2012) [15] studied the elderly who did not live with children and found that those seniors tended to report lower scores on self-rated health and satisfaction towards life; and they showed a higher likelihood of having ADL (activity of daily living) disabilities and were more likely to feel lonely. In contrast, the elderly who lived with others reported better self-rated health scores (L. W. Li, Zhang, \& Liang, 2009) [16]. Chen and Shot (2008) [17] examined the oldest old in China and found that those who lived with adult children, especially daughters, reported the best emotional health results. Those who lived alone showed the worst health outcomes. Wang and colleagues' (2014) [18] analysis further supported the finding that the elderly living with adult children tended to have better psychological well-being than those living alone. But they also indicated that such a beneficial effect only existed among the non-married oldest old in China. Moreover, a study on the elderly aged 80 and above who were institutionalized showed that the mortality rate of those living in institutions was 1.35 times higher than those who were not institutionalized (Gu, Dupre, \& Liu, 2007) [19].

Though the majority of the research has showed positive influence of household context on the elderly's health and subjective well-being, a few studies have demonstrated opposite results. For instance, Yang and Chandler (1992) [20] found that the lack of privacy due to co-residence and intergenerational conflicts led to negative impact of co-residence on the elderly's psychological well-being. When taking the living conditions into consideration, one analysis of 301 seniors in Wenzhou area of Zhejiang province showed that the subjective well-being of the elderly was highly influenced by the size of the residence the most, followed by other factors including living arrangements. Thus, co-residing in a small household damaged the elderly's subjective wellbeing (Q. Chen, Yu, \& Yang, 2012) [21].

Even if the existing literature has largely increased our knowledge on living arrangements and the elderly's subjective well-being, prior research has obvious limitations. First, most studies examined the influence of living arrangements on the elderly's subjective well-being without controlling for intergenerational relations. The interaction effects between living arrangements and intergenerational relations have rarely been considered. Indeed, living arrangements only represent a form of living choices among the elderly, which often interacts with other factors to affect the elderly's subjective well-being. Those factors include: relationship between adult children and the elderly, supporting that the elderly can possibly gain from the adult children, the way in which elderly interacts with other household members. Zhang, et al. (2004) [22], for example, indicated that care provided by children significantly impacted the elderly's health. Thus, studying living arrangements and the elderly's subjective well-being without considering the intergenerational relations will not be able to explore a complete picture of how the elderly's subjective well-being is impacted by their living arrangements. Secondly, prior research has rarely considered social participation of the elderly. Zhang's (2015) [23] research demonstrated that social par- 
ticipation has significantly lowered the likelihood of the elderly living with other family members. Chen and Chen (2012) [24] found that the elderly engaging in various degrees of social interaction with others and the environment leads to different levels of emotional dependence and perceived social support, which may influence the elderly's living arrangement patterns. These findings suggest that social participation may interact with living arrangements to cause various health outcomes.

This analysis intends to improve the literature on living arrangements and the elderly's well-being by incorporating intergenerational relations and social participation into the research scope. The study focuses on the elderly aged 65 years and above. Data are derived from the newly released 2011 wave of Chinese Longitudinal Healthy Longevity Survey (CLHLS). The paper begins by exploring the living arrangements of the elderly from 2011 to 2012. The paper then shows descriptive results of subjective well-being and other important covariates. Finally, regression analyses are conducted to explore whether living arrangements affect the elderly's subjective well-being when intergenerational relations and social participation are taken into consideration. I now turn to the introduction of data, measures and methods of the research.

\section{Data, Measures and Methods}

\subsection{Data}

Data used for this analysis are from newly released wave of the Chinese Longitudinal Healthy Longevity Survey (CLHLS), "the first large surveys of the oldest old conducted in a developing country" (Zeng, Vaupel, Xiao, Zhang, \& Liu, 2002: 252) [25]. The current research analyzes newly released data collected in 2011 and 2012. The CLHLS data were collected by Peking University's Center for Healthy Aging and Family Studies and the China National Research Center on Aging, with support from the US National Institute on Aging.

The 2011-2012 CLHLS wave was undertaken in more than 800 randomly selected counties and cities of the 23 provinces in China (Liaoning, Jilin, Heilongjiang, Beijing, Tianjin, Shanxi, Shaanxi, Shanghai, Jiangsu, Zhejiang, Anhui, Fujian, Jiangxi, Shandong, Henan, Hubei, Hunan, Guangdong, Guangxi, Sichuan, Chongqing and Hainan). The survey covers roughly half the counties and cities of those provinces and the sample areas represent $85 \%$ of the total population of China. In the 2011-2012 survey, 3802 male elderly and 4603 female elderly (for a total of 8405) surveyed in 2008 were reinterviewed. And 801 males and 982 females (for a total of 1783) were newly added interviewees. Thus, in the 2011 wave, 4603 males and 5585 females were included in the survey. In my analyses, I exclude those under 65 years of age, which yields a total number of studied elderly as 9679 ranged from 65 to 114 years old.

\subsection{Measures}

\section{1) Measuring living arrangements}

Living arrangements in this study is measured by three sub-categories: a) living with others, b) living alone, and c) living in institution. When I conduct regression analyses, I retreat those living with other household members as the reference category because "living with others" represents the majority of the surveyed respondents.

\section{2) Measuring subjective well-being}

The CLHLS includes a number of questions regarding the elderly's life evaluation. Those questions include: a) How do you rate your life at present? b) Do you always look on the bright side of things? c) Are you happy now as when you were younger? d) Do you often feel fearful or anxious? e) Do you often fell lonely and isolated? f) Do you feel the older you get the more useless you are? g) Have you felt sad, blue, or depressed for two weeks or more in last 12 months? h) Have you lost interest in most things, like hobbies, work, or similar activities? The responses range from 1 to 5 . " 1 " represents always or very good; " 5 " represents never or very bad. The items are recoded so that " 1 " indicates the weakest feel and " 5 " the strongest feel. Since CLHLS data were not collected to examine the psychological well-being of the elderly, the above question may not be "perfect indicators of one’s subjective well-being" (Chen and Shot, 2008: 1388) [17]. However, Chen and Shot (2008: 1388) [17] indicated that: "they represent important dimensions of subjective well-being, such as life satisfaction, happiness, and loneness." Thus, measures associated with the above questions as considered as legitimate indicators of the elderly's subjective well-being.

Following Chen and Shot (2008)'s [17] strategy of constructing indices of subjective well-being, in this analysis, three indices are created by adding items 1 to 3 as an index representing positive well-being, adding items 4 
to 6 as first index of negative well-being, and adding item 7 to 8 as second index of negative well-being. The above questions are considered as independent to each other. Thus, the indices are summary scores for each set of variables discussed above, which is created by adding the raw scores of all variables in each set. My logic behind the strategy is that each group of variables measures the same concept. This strategy reduces the number of variables in the analysis and improves the efficiency of the regression models that estimate the relationship between living arrangements and elderly's subjective well-being. After summing each set of variables to a single variable, I further rely on Cronbach's (1951) [26] alpha to assess the reliability of a given set of variables. The set of items is often referred to as a scale. The reliability alpha (Cronbach's alpha) is defined as the square of the correlation between the measured scale and the underlying factor. It we think of a test as "being composed of a random sample of items from a hypothetical domain of items designed to measure the same thing, alpha represents the expected correlation of one test with an alternative form containing the same number of items" (StataCorp LP, 2007, p. 29) [27]. The internal consistency coefficients for the three indices are alpha $=0.51$, $0.63,0.72$, respectively. The first two alpha values seem to be lower than the alpha value used in other research. But since only three items are used to construct the indices and the alpha value is positively related to number of items used, the alpha values are considered as acceptable. The alpha values and the items which are used to compose variables used in the analysis are specified in the Appendix.

\section{3) Measuring intergenerational relations and social participation}

In this analysis, measures of intergenerational relations and social participation are also included. The CLHLS had questions asking the elderly: a) Whom do you talk to frequently in daily life? b) To whom do you usually ask for help when you have problems or difficulties? c) Who is the first person that you talk to when you need to share your thoughts? d) Who took care of you when you are sick? The choices for answering the questions included: spouse, son, daughter, daughter-in-law, son-in-law, grandchildren and their spouses, other relatives, friends/neighbors, social workers, nanny and nobody. The respondent was asked to choose three from the above options. Based on the four questions, four variables are generated to represent the intergenerational relations between the elderly and their adult children, which are named as "chatting with children", "asking help from children", "sharing thoughts with children" and "taken care by children". If the respondent's answers include "children", then the four intergenerational variables are coded as " 1 ", and " 0 " if otherwise. Following the same strategy of constructing index, the alpha value is used to evaluate the internal consistency of the variables. The results show that the alpha value for the above four variables is 0.68 . I therefore consider the intergenerational relation variable as legitimate to use. The respondents who did not have children are coded as missing in the intergenerational index.

Social integration is measured by the question: "Do you take part in some social activities at present?" The options for the elderly to choose include: almost everyday, once a week, once a month, sometimes and never. Participating in social activities is coded as a continuous variable ranging from " 5 " to " 1 " (almost everyday = 5, never =1).

\section{4) Control variables}

In additional to the above measures, a number of variables are also controlled. These variables include the elderly's demographic characteristics, including age (which is measured in chronological years), gender, marital status (widowed, never married, divorced/separated), residence and ethnicity (Han vs. Non-Han). The elderly's socioeconomic status, measured by education and family income prior to the survey year, is also controlled. Besides the above controls, whether the elderly's spouse died in the past three/four years (after 2008 survey) is also controlled since it has been found to be significantly related to one's subjective well-being (Chen and Shot 2008) [17]. Moreover, the elderly's self-rated health (SRH), measured by a 5 -point scale ( $5=$ very good, $4=$ good, $3=$ so so, 2 = poor and 1 = very poor) and ADL (activity of daily living) disabilities are controlled as well. ADL disability is defined as whether the respondent had limitations in activities of daily living (ADL) at the 2011 wave. ADL is measured by six items (bathing, dressing, using the toilet, indoor transferring, eating, and controlling bladder and bowel movement). Being incapable to perform any of the six activities independently is considered as having ADL. The ADL score can therefore range from 0 to 6. I coded ADL into a categorical variable $(1=$ yes, $0=$ no).

\subsection{Methods}

Descriptive analysis strategy and ordinary least square (OLS) regression are applied to examine how living ar- 
rangements impact elderly subjective well-being when demographic and other factors are controlled. Particularly, in the regression models, interaction terms of living arrangements and social participation, and living arrangements and intergenerational relations are included to test whether intergenerational relations and social participation are mediators through which living arrangements lead to various subjective well-being outcomes. Regression coefficients are reported here but tables with standard errors are available upon request.

\section{Results}

\subsection{Living Arrangements of the Sampled Elderly}

The paper first summarizes the living arrangements of sampled elderly in 2011 to 2012 by referring to Table 1 . The data show the variation of living arrangement patterns for elderly in China aged 65 and above. As discussed earlier, three types of living arrangements are classified in this research, which include: 1) living alone, 2) living with others, and 3) institutionalization (mainly nursing homes). The living arrangements of elderly are demonstrated by residence, gender and age. As the table shows, for both male and female elderly individuals, living with other household members is the modal category (around 80\%) regardless of their residence (rural or urban), gender or age. Overall, only about $2 \%$ of the sampled elderly lived in institutions. The rest of the elderly chose to live alone.

Diversity, however, exists with regard to living arrangements among the subgroups. Specifically, men and urban residents are more likely to live with household members as compared to women and rural residents (83.3\% vs. $79.1 \%$; $82 \%$ vs. $80 \%$ ). This is perhaps due to a higher marriage rate of men than women since living with spouse is also included in the "living with other household members" category. Accordingly, women and rural residents showed higher percentages of living alone (18.6\% vs. $14.8 \%$; $18.6 \%$ vs. $18.7 \%$ vs. $14.9 \%)$. Meanwhile, urban residents also reported a higher percentage of being institutionalized than their rural counter parts (3.1\% versus $1.3 \%$ ). When age is taken into consideration, the percentage of elderly who were institutionalized increased with age. Interestingly, the age group 75 to 84 instead of 65 to 74 reported the highest percentage of living alone (20.5\%). As compared to the other two age groups, elderly aged 65 to 74 are more likely to live with other household members. In summary, an overwhelmingly higher percent of the elderly chose to live with other household members, although their living arrangement patterns vary by sex, age and residence. The variation of living arrangements shown in Table 1 points to the necessity of testing how different living arrangements lead to variation in elderly's subjective well-being.

\subsection{Description of the Sample}

The descriptive results of the independent and control variables are shown in Table 2. In terms of the subjective well-being variables, on average, males and urban residents show better subjective well-being scores than their female and rural counterparts. When it comes to intergenerational relations, females and rural seniors reported better intergenerational relation scores as compared to males and urban elderly. Interestingly, the intergenerational relation scores also increase with age. It means that with age increasing, the reported intergenerational relations tend to be better. As to the mediating variables, the level of social participation varies by demographics. Overall, the majority of the respondents (86.1\%) reported not taking part in social activities. Females and rural

Table 1. Percentage distribution of living arrangements among elderly aged 65 and over: China, 2011-2012.

\begin{tabular}{|c|c|c|c|c|c|c|c|}
\hline \multirow{2}{*}{ Living Arrangements } & \multicolumn{2}{|c|}{ Sex } & \multicolumn{2}{|c|}{ Residence } & \multicolumn{3}{|c|}{ Age Group } \\
\hline & Male & Female & Urban & Rural & $65-74$ & $75-84$ & $85+$ \\
\hline Living with household members & 83.3 & 79.1 & 82.0 & 80.0 & 85.8 & 78.1 & 80.3 \\
\hline Living alone & 14.8 & 18.6 & 14.9 & 18.7 & 13.5 & 20.5 & 16.6 \\
\hline Institution & 2.0 & 2.3 & 3.1 & 1.3 & 0.7 & 1.4 & 3.1 \\
\hline $\mathrm{N}$ & 4349 & 5288 & 4571 & 5066 & 1911 & 2526 & 5115 \\
\hline
\end{tabular}

Source: CLHLS wave 2011. 
Table 2. Descriptive analysis of independent and control variables for elderly aged 65 and over: China, 2011-2012.

\begin{tabular}{|c|c|c|c|c|c|c|c|c|}
\hline \multirow{2}{*}{ Variables } & \multirow{2}{*}{ Total } & \multicolumn{2}{|c|}{ Sex } & \multicolumn{2}{|c|}{ Residence } & \multicolumn{3}{|c|}{ Age Group } \\
\hline & & Male & Female & Urban & Rural & $65-74$ & $75-84$ & $85+$ \\
\hline \multicolumn{9}{|l|}{ Subjective well-being variables (mean) } \\
\hline 1) Positive well-being & 11.1 & 11.2 & 11.0 & 11.3 & 10.9 & 11.2 & 11.1 & 11.1 \\
\hline 2) Negative well-being I & 6.9 & 6.4 & 6.9 & 6.5 & 6.9 & 6.3 & 6.6 & 7.0 \\
\hline 3) Negative well-being II & 0.24 & 0.21 & 0.27 & 0.25 & 0.24 & 0.26 & 0.28 & 0.22 \\
\hline Intergenerational relation index (mean) & 2.1 & 2.0 & 2.3 & 2.1 & 2.2 & 1.6 & 2.0 & 2.4 \\
\hline \multicolumn{9}{|l|}{$\underline{\text { Social participation variable }}$} \\
\hline \multicolumn{9}{|l|}{ Social integration (\%) } \\
\hline $1=$ yes & 13.9 & 18.0 & 12.5 & 18.7 & 9.6 & 23.7 & 18.4 & 8.0 \\
\hline $0=$ no & 86.1 & 82.0 & 89.5 & 81.3 & 90.4 & 76.3 & 81.6 & 92.0 \\
\hline \multicolumn{9}{|l|}{$\underline{\text { Control variables }}$} \\
\hline \multicolumn{9}{|l|}{ 1) Currently married (\%) } \\
\hline $1=$ yes & 61.8 & 57.3 & 22.6 & 38.4 & 38.2 & 74.0 & 52.0 & 17.3 \\
\hline $0=$ no & 38.2 & 42.7 & 77.4 & 61.6 & 61.8 & 26.0 & 48.0 & 82.7 \\
\hline \multicolumn{9}{|l|}{ 2) Minority (\%) } \\
\hline $1=$ yes & 5.9 & 5.4 & 6.3 & 4.8 & 6.9 & 5.8 & 5.7 & 6.0 \\
\hline $0=$ no & 94.1 & 94.6 & 93.7 & 95.2 & 93.1 & 94.2 & 94.3 & 94.0 \\
\hline \multicolumn{9}{|l|}{ 3) Sex (\%) } \\
\hline 1 = Male & 45.0 & - & - & 45.9 & 44.3 & 55.3 & 51.3 & 37.6 \\
\hline $0=$ Female & 55.0 & - & - & 54.1 & 55.7 & 44.7 & 48.7 & 62.4 \\
\hline \multicolumn{9}{|l|}{ 4) Urban (\%) } \\
\hline $1=$ yes & 47.3 & 48.2 & 46.6 & - & - & 46.7 & 49.4 & 47.1 \\
\hline $0=$ no & 52.7 & 51.2 & 53.4 & - & - & 53.3 & 50.6 & 52.9 \\
\hline 5) Age & 86.0 & 83.3 & 88.1 & 85.8 & 86.2 & - & - & - \\
\hline 6) Self-rated health & 3.3 & 3.4 & 3.3 & 3.4 & 3.3 & 3.4 & 3.3 & 3.4 \\
\hline \multicolumn{9}{|l|}{ 7) ADL (\%) } \\
\hline $1=$ yes & 26.4 & 20.3 & 31.5 & 24.0 & 29.1 & 31.7 & 31.5 & 10.2 \\
\hline $0=$ no & 73.6 & 79.7 & 68.5 & 76.0 & 70.9 & 68.3 & 68.5 & 89.8 \\
\hline 8) Household income of last year & 24,869 & 25,622 & 24,238 & 30,703 & 19,679 & 24,134 & 24,562 & 25,342 \\
\hline 9) Education & 2.3 & 3.9 & 1.0 & 2.9 & 1.8 & 4.2 & 2.5 & 1.4 \\
\hline \multicolumn{9}{|l|}{ 10) If spouse died in past 2 years } \\
\hline $1=$ yes & 10.8 & 9.4 & 11.8 & 10.5 & 11.0 & 7.4 & 10.5 & 12.1 \\
\hline $0=$ no & 89.2 & 11.8 & 88.2 & 89.5 & 89.0 & 92.3 & 89.5 & 87.9 \\
\hline
\end{tabular}

Source: CLHLS wave 2011. $\mathrm{N}=9679$. 
residents tend to participation in social activities less and the level of social participation decreases with age.

The control variables show variations among the elderly subgroups. As to the marital status of the respondents, males reported a much higher percentage of being married than females (57.3\% vs. 22.6\%). There is no significant rural and urban difference in marital status. The distribution of Han majority and non-Han minorities are about equal among subgroups. There are a slightly higher percentage of them living in urban areas than rural areas $(52.7 \%$ vs. $47.3 \%)$. The mean age of the sampled 9679 elderly is 85.9 and the respondents' ages range from 65 to 114. There are also more females who were interviewed in the survey than males (55\% vs. 45\%). When it comes to the health status of the elderly, the average self-rated health (SRH) of the elderly is 3.3, meaning on average, the sampled Chinese elderly self-rated their health status as anywhere between "so-so" to "good". There are higher percentages of females (31.5\%) and rural residents (29.1\%) reported having ADL disabilities. The oldest-old show the lowest percentage reporting ADL disabilities (10.2\%) as compared to other two age groups. The socioeconomic status of the subgroups differs considerably. The urban elderly reported an average household income prior to the survey year as 30,703 RMB, which is way above the average household income reported by the overall sample. In contrast, their rural counterparts only reported an average household income in the same year as 19,679 RMB. As to educational attainments, males, urban residents and younger elderly all claimed a greater number of years of schooling. Overall, $10.8 \%$ of the respondents reported having spouses died since the survey year of 2008. Females and rural elderly reported higher percentages of spouse's death and the reported percentage also increases with age. After showing the differentiation among subgroups in various dimensions, the paper now turns to the regression analyses of living arrangements and elderly's subjective well-being.

\subsection{Regression Results}

Table 3 provides the OLS regression coefficients on positive and negative well-being. In models 1, 3, and 5, only the living arrangement variables along with the control variables are included. The rest of the models further add social participation and intergenerational relation variables as well as the interaction terms between living arrangements and the two mediating variables to evaluate the influence of these two mediating variables. The regression models examine the subjective well-being of those living with other household members as compared to the subjective well-being of those who lived alone or lived in institution. The analysis focuses on the effects of intergenerational relations and the elderly's social participation on their subjective well-being.

Findings show that after controlling for age, sex, marital status, ethnicity, urban residence, ADL, household income, SRH and whether spouse died in past three years, living arrangements only show significant effects on negative well-being but not on positive well-being. In particular, holding other variables constant, as compared to those living with household members, living alone increases the first and second negative well-being index scores by $35 \%$ and $6 \%$, respectively. In a similar vein, living in an institution raises the two negative well-being scores by $54 \%$ and $5 \%$, respectively. The results imply that living with others significantly decreases the negative well-being among the Chinese elderly. These findings corroborate findings of the existing literature that the household context provides a protective effect on subjective well-being.

After the two mediating variables, social participation and intergenerational relations, and the interaction terms are included in the models, interesting findings emerge. A higher level of social participation and better intergenerational relations significantly promote the elderly's positive well-being and reduce their negative well-being. Specifically, participating in social activities increases the respondent's positive well-being by $22 \%$ and diminishes the negative well-being by $14 \%$. Everything else being equal, a better intergenerational relation raises the positive feeling index by $6 \%$ and reduces the negative feeling index by $2 \%$. These finding show that both social integration and intergenerational relation variables are important factors that need to be considered when studying living arrangements and elderly's subjective well-being. The importance of these two factors has not been recognized and fully explored in previous analyses. When the interaction terms between living arrangements and the two mediating variables are taken into consideration, the results show that the interaction terms are not significant when predicting the elderly's positive well-being. Also, the interaction term between living arrangements and intergenerational relations is not significant in either model. Instead, the interaction term between living arrangements and social participation becomes significant when predicting negative well-being. Thus, in the regression models 3 through 6 , the no-significant interaction terms between living 
Table 3. OLS regression on positive and negative well-being among Chinese elderly aged 65 and over: 2011-12.

\begin{tabular}{|c|c|c|c|c|c|c|}
\hline \multirow{2}{*}{ Variables } & \multicolumn{2}{|c|}{$\begin{array}{c}\text { Positive } \\
\text { Well-being }\end{array}$} & \multicolumn{2}{|c|}{$\begin{array}{c}\text { Negative } \\
\text { Well-being I }\end{array}$} & \multicolumn{2}{|c|}{$\begin{array}{c}\text { Negative } \\
\text { Well-being II }\end{array}$} \\
\hline & Model 1 & Model 2 & Model 3 & Model 4 & Model 5 & Model 6 \\
\hline \multicolumn{7}{|c|}{ Living arrangement variable (ref. = living with others) } \\
\hline 1) Living with others & - & - & - & - & - & - \\
\hline 2) Living alone & -0.06 & -0.18 & $0.37 * * *$ & $0.35^{* * *}$ & $0.06^{* *}$ & $0.06^{*}$ \\
\hline 3) In institution & 0.07 & -0.35 & 0.14 & $0.54 *$ & $0.17^{* *}$ & 0.05 \\
\hline Intergenerational relation index & & $0.06^{* * *}$ & & -0.01 & & $-0.02 *$ \\
\hline$\underline{\text { Social participation variable }}$ & & $0.22^{* *}$ & & $-0.14^{*}$ & & -0.01 \\
\hline \multicolumn{7}{|l|}{ Interaction terms } \\
\hline 1) Alone*intergenerational relation & & 0.04 & & - & & - \\
\hline 2) Alone*social participation & & 0.11 & & 0.02 & & 0.02 \\
\hline 3) Institution*intergenerational relation & & 0.04 & & - & & - \\
\hline 4) Institution*social participation & & 0.09 & & $-0.50 *$ & & $-0.10^{*}$ \\
\hline \multicolumn{7}{|l|}{$\underline{\text { Control variables }}$} \\
\hline 1) Currently married & $0.13^{*}$ & 0.06 & $-0.39 * * *$ & $-0.40 * * *$ & $-0.04 *$ & $-0.07 * * *$ \\
\hline 2) Minority & $-0.24 *$ & $-0.23^{*}$ & $0.26^{*}$ & $0.29 *$ & -0.04 & -0.04 \\
\hline 3) Male & $-0.14^{* *}$ & $-0.13^{* *}$ & -0.09 & -0.09 & -0.02 & -0.02 \\
\hline 4) Urban & $0.16^{* *}$ & $0.12^{* *}$ & $-0.22 * * *$ & $-0.21 * * *$ & $-0.03^{*}$ & $-0.03^{*}$ \\
\hline 5) Age & $0.01 *$ & 0.01 & -0.01 & -0.01 & $-0.01^{* * *}$ & $-0.01^{* * *}$ \\
\hline 6) Household income & $0.01 * * *$ & $0.01 * * *$ & $-0.01 * * *$ & $-0.01^{* * *}$ & $-0.01 * * *$ & $-0.01 * * *$ \\
\hline 7) Education & $0.04 * * *$ & $0.04 * * *$ & $-0.04 * * *$ & $-0.04 * * *$ & -0.01 & -0.01 \\
\hline 8) Self-rated health & $10.0 * * *$ & $10.0 * * *$ & $-0.76^{* * *}$ & $-0.74^{* * *}$ & $-0.16^{* * *}$ & $-0.16^{* * *}$ \\
\hline 9) ADL disabilities & $-0.11^{* * *}$ & $-0.10^{* * *}$ & $0.20 * * *$ & $0.20 * * *$ & $0.03^{* * *}$ & $0.04 * * *$ \\
\hline 10) Spouse dead, $\leq 3$ years & -0.09 & -0.03 & 0.11 & 0.09 & $0.05^{*}$ & 0.03 \\
\hline Constant & $6.9 * * *$ & $6.9 * * *$ & $9.6 * * *$ & $9.7 * * *$ & $1.3^{* * *}$ & $1.4^{* * *}$ \\
\hline $\mathrm{N}$ & 5624 & 5356 & 5713 & 5437 & 5030 & 4803 \\
\hline Adjusted R2 & 0.27 & 0.27 & 0.19 & 0.19 & 0.08 & 0.08 \\
\hline
\end{tabular}

Source: see Table $1 . *<0.1, * *<0.05, * * *<0.01$.

arrangements and intergenerational relations are dropped. Only the interaction terms between living arrangements and social participation are kept in these models. The significant interaction terms suggest that social participation decreases the negative well-being of those living in institutions. For example, model 4 shows that compared to those who lived with others, for those who lived in institutions, participating in social activities decreases their two separate negative feeling indices by $50 \%$ and $10 \%$, respectively. Such results highlight the role of social participation in reducing negative well-being among those who did not live in a family household. Coefficients for most control variables are significant, suggesting that married, Han, well-educated and urban elderly along with those who were economically doing well and rated their health better tended to have more positive well-being than those who were not married, minority, poorly-educated and rural elderly as well as people with lower economic status and ADL disabilities.

Clearly these results suggest that the Chinese elderly's subjective well-being is in part associated with differ- 
ences in living arrangements and the elderly's social integration level and their relationships with children, even after controlling for the elderly's demographic features. The results emphasize that as compared to those who lived with other household members, Chinese elderly who lived alone or lived in institutions were more likely to report negative well-being. However, social participation can be an important factor that mediates with living arrangements to reduce the negative well-being, particularly for those who were institutionalized.

\section{Conclusion and Discussion}

Prior research has repeatedly documented that living in a household context promotes the elderly's subjective well-being (see discussion in the introduction section). This research intends to examine when the elderly's social integration and intergenerational relations are taken into consideration, how the elderly's living arrangement patterns influence their subjective well-being. Particularly, the research studies how living arrangements interact with the elderly's social integration as well as intergenerational relations to affect an individual subjective well-being. In summary, the findings corroborate previous findings that living alone or living in an institution damages the Chinese elderly's well-being. Some new findings also emerge when social participation and intergenerational relations are brought into the analytical scope. A higher level of social participation and better intergenerational relations promote positive well-being and reduce negative well-being. However, only social participation interacts with living arrangements when influencing the elderly's subjective well-being. Specifically, participating in social activities decreases negative well-being of the elderly who lived in institutions.

These findings contribute to aging studies by raising some important concerns. First and foremost, in most Asian countries, the family household has long been considered as an important component of a society that supports people when they age. This tradition is strongly linked to Confucianism and filial piety culture in those Asian societies. But with modernization characterized by the demise of the extended family, increased labor force participation of women and labor mobility, informal care provided by family members diminishes. More elderly people will perhaps choose to live in institutions in the future. Meanwhile, with nuclear family replacing extended families, more seniors may face the situation of living alone. Then would this transition damage the elderly's well-being? The answer is yes and no. Findings of this research and previous analyses seem to support the argument that not living in a household context diminishes the elderly's well-being. But there are other factors that may compensate this negative effect of living arrangements on subjective well-being. This research shows that social integration can be an important factor that reduces negative feelings linked to living arrangement patterns.

Secondly, should intergenerational relations be excluded from future analysis of the elderly's subjective well-being? This current research initially expected that the negative well-being should decrease for those individuals who lived alone or lived in institutions if they had better intergenerational relations. Nevertheless, the coefficients for the specific interaction term turn to be non-significant. This result must be interpreted with caution. This is because the intergenerational index constructed in this analysis may not be the best one that captures the relationship between the elderly and their adult children. Thus, the author suggests future research using different measures to re-test this hypothesis.

Thirdly, does the protective effect of co-residence only exist among non-married individuals? Wang and colleagues' (2014) [18] analysis showed that the elderly living with adult children tended to have better psychological well-being than those living alone. But they indicated that such a beneficial effect only existed among the non-married oldest old in China. The results of my research support Wang and his colleagues' findings by showing the important role of being currently married on subjective well-being. But my research does point out that even after controlling for marital status, living arrangements still strongly link to the elderly's subjective well-being. This finding suggests that the impact of living arrangements on subjective well-being may be independent of the elderly's marital status.

Besides marriage, the research also emphasizes that higher socioeconomic status, urban residency and better health status improve subjective well-being. The elderly who are in a disadvantaged socioeconomic position, rural and with worse health are more likely to report negative well-being as well. Indeed, those individuals are also more likely to live alone, lacking family care and having a higher risk of being institutionalized (Zhang 2015) [23]. These findings emphasize that to promote the elderly's well-being, future research and policy makers may need to focus more on those socioeconomically disadvantaged groups. Policy makers and senior programs should also devote more resources to such groups. 
One interesting finding worth mentioning here is that living arrangements only show significant effects on negative well-being but not positive well-being. This finding adds an important addition to the existing literature. It implies that living with others may only have a protective effect on negative feelings but it does not promote positive well-being. This research did not break down the elderly who lived with others to subgroups, such as living with spouse only, living with daughters, living with sons, et al. Though subgroups are not classified, the findings are still believed to be robust since Chen and Shot (2008) [17] did suggest that regardless of what kinds of living arrangements are classified, living in a household context benefits the elderly's well-being. One limitation of the research is that the current analysis examines samples from the 2011 wave of CLHLS. The data are largely cross-sectional in nature. The results have not taken a longitudinal scope and household dynamics into the analytical scope. Future research may extend the analysis to longitudinal studies and explore how household characteristics along with other factors enhance the elderly's well-being.

\section{Funding}

Supported by Program for Young Innovative Research Team in China University of Political Science and Law.

\section{Note}

Data used for this research were provided by the Chinese Longitudinal Healthy Longevity Survey (CLHLS), managed by the Center for Healthy Aging and Family Studies, Peking University. This survey is supported in part by funds from Duke University under an award from the US National Institutes of Aging and by the matching support of Chinese institutions.

\section{References}

[1] Davis, M.A., Neuhaus, J.M. and Mortitz, D.J. (1997) Living Arrangements, Changes in Living Arrangements, and Survival among Community Dwelling Older Adults. American Journal of Public Health, 87, 371-377. http://dx.doi.org/10.2105/AJPH.87.3.371

[2] Kasper, J. and Pearson, J.L. (1995) Living Arrangements, Social Integration, and Personal Control: Correlates of Life Satisfaction among Older People. Journal of Mental Health Aging, 1, 21-34.

[3] Magaziner, J., Cadigan, D.A., Hebel, J.R. and Parry, R.E. (1988) Health and Living Arrangements among Older Women: Does Living Alone Increase the Risk of Illness? Journal of Gerontology, 43, M127-M133. http://dx.doi.org/10.1093/geronj/43.5.M127

[4] Sarwari, A.R., Fredman, L. and Langenberg, P. (1998) Prospective Study on the Relation between Living Arrangement and Change in Functional Health Status of Elderly Women. American Journal of Epidemiology, 147, 401-406. http://dx.doi.org/10.1093/oxfordjournals.aje.a009459

[5] Hughes, M.E. and Waite, L.J. (2002) Health in Household Context: Living Arrangements and Health in Late Middle Age. Journal of Health and Social Behavior, 43, 1-21. http://dx.doi.org/10.2307/3090242

[6] Lawton, M.P., Moss, M. and Kleban, M.H. (1984) Marital Status, Living Arrangements and the Well-Being of Older People. Research on Aging, 6, 323-345. http://dx.doi.org/10.1177/0164027584006003002

[7] Sereny, M.D. and Gu, D. (2011) Living Arrangement Concordance and Its Association with Self-Rated Health among Institutionalized and Community-Residing Older Adults in China. Journal of Cross Culture Gerontology, 26, $239-259$. http://dx.doi.org/10.1007/s10823-011-9145-y

[8] Zimmer, Z. (2005) Health and Living Arrangement Transitions among Chinese Oldest-Old. Research on Aging, 27, 526-555. http://dx.doi.org/10.1177/0164027505277848

[9] Lund, R., Due, P., Modving, J., Holstein, B.E., Damsgaard, M.T. and Anderson, P.K. (2002) Cohabitation and Marital Status as Predictors of Mortality. Social Science \& Medicine, 55, 673-679. http://dx.doi.org/10.1016/S0277-9536(01)00219-2

[10] Zunzunegui, M., Beland, F. and Otero, A. (2001) Support from Children, Living Arrangements, Self-Rated Health and Depressive Symptoms of Older People in Spain. International Journal of Epidemiology, 30, 1090-1099. http://dx.doi.org/10.1093/ije/30.5.1090

[11] Rook, K.S. (1984) The Negative Side of Social Interaction: Impact on Psychological Well-Being. Journal of Gerontology, 46, 1097-1108.

[12] Rook, K.S. and Pietromonaco, P. (1987) Close Relationship: Ties That Heal or Ties that Bind? Advances in Personal Relationships, 1, 1-35. 
[13] Krause, N. and Liang, J. (1993) Stress, Social Support, and Psychological Distress among the Chinese Elderly. Journal of Gerontology, 48, P282-P291. http://dx.doi.org/10.1093/geronj/48.6.P282

[14] Michael, Y.L., Berkman, L.F., Gold, G.A. and Kawachi, I. (2001) Living Arrangements, Social Integration and Change in Functional Health Status. American Journal of Epidemiology, 153, 123-131. http://dx.doi.org/10.1093/aje/153.2.123

[15] Li, J. and Li, J. (2012) Life Quality of Urban Empty-Nested Elderly (ChengshiKongchaoLaorenShenghuoZhiliangYanjiu). Population Journal (RenkouXuekan), 3, 31-41. (In Chinese)

[16] Li, L.W., Zhang, J. and Liang, J. (2009) Health among the Oldest-Old in China: Which Living Arrangements Make a Difference? Social Science \& Medicine, 68, 220-227. http://dx.doi.org/10.1016/j.socscimed.2008.10.013

[17] Chen, F. and Shot, S.E. (2008) Household Context and Subjective Well-Being among the Oldest Old in China. Journal of Family Issues, 29, 1379-1403. http://dx.doi.org/10.1177/0192513X07313602

[18] Wang, J., Chen, T. and Han, B. (2014) Does Co-Residence with Adult Children Associate with Better Psychological Well-Being among the Oldest Old in China? Aging \& Mental Health, 18, 232-239. http://dx.doi.org/10.1080/13607863.2013.837143

[19] Gu, D., Dupre, M.E. and Liu, G. (2007) Characteristics of the Institutionalized and Community-Residing Oldest-Old in China. Social Science \& Medicine, 64, 871-883. http://dx.doi.org/10.1016/j.socscimed.2006.10.026

[20] Yang, H. and Chandler, D. (1992) Intergenerational Relations: Grievances of the Elderly in Rural China. Journal of Comparative Family Studies, 23, 431-453.

[21] Chen, Y.-J. and Chen, C.-Y. (2012) Living Arrangement Preferences of Elderly People in Taiwan as Affected by Family Resources and Social Participation. Journal of Family History, 37, 381-394. http://dx.doi.org/10.1177/0363199012440948

[22] Zhang, Z. (2004) The Impact of Adult Children Providing Care on the Elderly's Health: Promotion or Selection (ZinuZhaoliao Dui LaonianrenJiankang De Yingxiang: CuijinHaishiXuanze)? Chinese Population Sciences (ZhongguoRenkouKexue), Suppl., 29-36. (In Chinese)

[23] Zhang, L. (2015) Determinants of Living Arrangements among the Chinese Elderly: New Evidence from the CLHLS 2011Wave. Chinese Studies, 4, 32-43. http://dx.doi.org/10.4236/chnstd.2015.41006

[24] Chen, Q., Yu, C. and Yang, S. (2012) Investigation on Health Influencing Factors and Health Demand of Elderly in Different Living Situations. Chinese Nursing Research, 26, 1463-1465. (In Chinese)

[25] Zeng, Y., Vaupel, J.W., Xiao, Z., Zhang, C. and Liu, Y. (2002) Sociodemographic and Health Profiles of the Oldest Old in China. Population and Development Review, 28, 251-273. http://dx.doi.org/10.1111/j.1728-4457.2002.00251.x

[26] Cronbach, L.J. (1951) Coefficient Alpha and the Internal Structure of Tests. Psychometrika, 16, 151-160. http://dx.doi.org/10.1007/BF02310555

[27] StataCorp, L.P. (2007) Stata 10 Manual, Reference A-H. Stata Press, College Station. 
Appendix. Scale items and alpha coefficients.

\begin{tabular}{|c|c|c|}
\hline$\underline{\text { Variables }}$ & $\underline{\text { Individual Items }}$ & $\underline{\text { Alpha Values }}$ \\
\hline \multirow[t]{3}{*}{ Positive feelings } & Q1: How do you rate your life at present? & 0.51 \\
\hline & Q2: Do you always look on the bright side of things? & \\
\hline & Q3: Do you feel happy as younger? & \\
\hline \multirow[t]{3}{*}{ Negative feelings I } & Q4: Do you feel fearful or anxious? & 0.63 \\
\hline & Q5: Do you feel lonely and isolated? & \\
\hline & Q6: Do you feel useless as age? & \\
\hline \multirow[t]{2}{*}{ Negative feelings II } & Q7: Have you felt sad, blue, or depressed for two weeks or more in last 12 months? & 0.72 \\
\hline & Q8: Have you lost interest in most things like hobbies, work, or similar activities? & \\
\hline \multirow[t]{4}{*}{ Intergenerational relations } & Q9: To whom do you usually talk frequently in daily life? & 0.68 \\
\hline & Q10: The $1^{\text {st }}$ person you ask for help when you have difficulties/problems? & \\
\hline & Q11: $1^{\text {st }}$ person to whom you talk when you need to share your thoughts? & \\
\hline & Q12: Who took care of you when you are sick? & \\
\hline
\end{tabular}

